OPEN ACCESS

Edited by:

Venkata Bharadwaj Kolli,

Creighton University, USA

Reviewed by: Katerina Maniadaki, Technological Educational Institute of Athens, Greece

Johnson Pradeep,

St. Johnson Medical College Hospital,

India

*Correspondence:

Helena M. Calii,

Departamento de Psicobiologia,

Universidade Federal de São Paulo (UNIFESP), Rua Napoleão de Barros, 925 - Vila Clementino, São Paulo, SP 04024-002, Brazil hmcali@unifesp.br

Specialty section:

This article was submitted to Child and Neurodevelopmental Psychiatry,

a section of the journal

Frontiers in Psychiatry

Received: 14 May 2015 Accepted: 14 September 2015 Published: 02 October 2015

Citation:

Palma SMM, Natale ACMP and Calil HM (2015) A 4-year follow-up study of attention-deficit hyperactivity

symptoms, comorbidities, and psychostimulant use in a Brazilian sample of children and adolescents with attention-deficit/hyperactivity disorder.

Front. Psychiatry 6:135 doi: 10.3389/fpsyt.2015.00135

\section{A 4-year follow-up study of attention-deficit hyperactivity symptoms, comorbidities, and psychostimulant use in a Brazilian sample of children and adolescents with attention-deficit/hyperactivity disorder}

\author{
Sonia M. M. Palma ${ }^{1}$, Ana Carolina M. P. Natale ${ }^{2}$ and Helena M. Calil ${ }^{1 *}$ \\ ${ }^{1}$ Department of Psychobiology, Universidade Federal de São Paulo (UNIFESP), São Paulo, Brazil, ${ }^{2}$ Universidade Mackenzie, \\ São Paulo, Brazil
}

The aim of this study was to evaluate symptom persistence in attention-deficit/ hyperactivity disorder (ADHD), the development of comorbidities, and psychostimulant usage patterns. Follow-up studies were conducted in 37 patients with ADHD and 22 healthy controls, aged 10 and 18, 4 years after their first assessment. The ADHD was rated as persistent if participants met all DSM-IV criteria for syndromic or sub-threshold persistence, or had functional impairments (functional persistence). Of the 37 ADHD patients we reevaluated, $75 \%$ had persistent symptoms, and psychiatric comorbidities with additional functional impairments and academic problems were more common than in controls. These follow-up findings show a high comorbidity associated with ADHD and support the importance of evaluation and treatment for ADHD and comorbidities throughout life.

Keywords: ADHD, comorbidity, follow-up, remission, school dropout, psychostimulant

\section{Introduction}

Attention-deficit/hyperactivity disorder (ADHD) is a childhood-onset neurodevelopmental condition characterized by age-inappropriate levels of inattention, hyperactivity, and impulsivity (1), and it is the most common of the neurodevelopmental disorders (2). It is multifactorial and clinically heterogeneous (3), with a worldwide prevalence rate of $5.3 \%$ (4) and a prevalence rate of $5-10 \%$ in school-aged children $(5,6)$.

Although ADHD is a neurodevelopmental disorder, hyperactivity-impulsivity symptoms declined with increasing age, but inattention symptoms did not (7-9), and many patients maintain symptoms into adolescence (75\%) and adulthood (66\%) (10-12).

Moreover, ADHD is frequently associated with psychiatric comorbidities, such as anxiety disorders $(30-40 \%),(13,14)$, and conduct disorder (CD)/oppositional defiance disorder (ODD) (30-50\%), (10). Psychiatric comorbidities might influence the clinical presentation of ADHD and may hinder the differential diagnosis of disorders. Diagnoses of ADHD can be easily confused 
if symptoms of impulsivity are decreased with anxiety or if symptoms of inattention are seen as secondary to comorbid psychiatric conditions (15).

Thus, the persistence of ADHD symptoms is a risk factor for a number of adverse outcomes in adolescence and adulthood, especially when there are comorbidities. It is associated with continuing social, educational, occupational, interpersonal difficulties, substance use disorders, driving difficulties and accidents, and delinquency problems $(1,8,16-18)$. Thus, the associations between the high prevalence, the persistence of symptoms, and the presence of comorbidities make the study of ADHD very interesting, important, and challenging.

There have been several follow-up studies of children documenting the persistence of ADHD into adolescence and adulthood (7, 12, 19-34). However, almost all of these studies were conducted in clinical samples in North America. Culture can affect different aspects of development, such as language development, behavioral expectations, parental tolerance for non-compliant behaviors, emotional regulation, binding styles, identity formation, motivation, and other aspects of parenting and early childhood education (35). Therefore, the diagnosis of ADHD and its evolution may be affected by cultural factors. Thus, it is difficult to generalize these results to other countries. In Brazil, there is a lack of follow-up of patients with ADHD diagnoses. A brief survey of the literature found only two follow-up studies in our country, by the same group of researchers $(25,36)$.

Thus, a prospective longitudinal follow-up study was designed to (a) investigate ADHD symptom persistence and full remission over these 4 years and to (b) track comorbidities and psychostimulant use.

\section{Materials and Methods}

The project was approved by the Research Ethics Committee of UNIFESP-HSP (protocol \# 1616/06). All patients, healthy controls, and their families were informed of the procedures involved. Those who agreed to participate signed an informed consent form.

\section{Baseline}

The baseline sample was selected from January 2007 to December 2007. This sample included children and adolescents with ADHD, visiting the Interdisciplinary Neuropsychological Child Care Center (NANI), Department of Psychobiology, UNIFESP. NANI is an outpatient facility specialized in interdisciplinary research on diagnosing neurodevelopmental disorders, delivering care, researching and teaching, specialized in ADHD. The sample at baseline consisted of 38 patients ( 31 boys, 7 girls), diagnosed with $\mathrm{ADHD}$ at a mean age of 8.7 years $(\mathrm{SD}=2.3)$. The healthy subjects were matched to the ADHD patients for gender, age, level of education, and type of school attended (i.e., public or private). Their mean age was 8.8 years $(\mathrm{SD}=1.8)$.

The inclusion criteria were as follows: (1) a full diagnosis of ADHD according to DSM-IV, (2) no comorbid mental disorders, (3) no history of psychostimulant medication use or any other medication that might interfere with cortisol secretion, (4) no history of a serious medical illness, and (5) an IQ score higher than 75 points. These strict criteria were responsible for the small number of participants.

\section{Follow-Up}

At follow-up, 4 years later, 37 patients ( 30 boys and 7 girls) and 22 healthy subjects (15 boys and 7 girls) were included. Their ages ranged from 10 to 18 . They were contacted by mail, e-mail, telephone, or through their school. In the ADHD group, there was a loss of one patient for failure to locate. The control group lost 16 children and adolescents, 8 for failure to locate and 8 because the family refused to participate in the research.

\section{Diagnostic Evaluation \\ Baseline}

The diagnosis of ADHD was based on the application of a Brazilian version of the SNAP-IV (Swanson, Nolan e Pelham - version IV) and the Child Behavior Checklist (CBCL). The SNAP-IV is a questionnaire consisting of symptoms from the Diagnostic and Statistical Manual - Fourth Edition - DSM-IV (37) that has already been validated in Brazil (38). The CBCL is a questionnaire that assesses social competence and behavioral problems from ages 4 to 18 years, from information provided by the parents, previously validated in Brazil (39). Both were answered by parents or guardians. A social evaluation was conducted with the Brazil Criteria of Economic Classification, a self-reported questionnaire - the ABEP (40). All assessments were conducted by two board-certified medical doctors (one psychiatrist and one pediatric neurologist) with many years of experience (over 25 years) in clinical evaluation and research. The children underwent a battery of neuropsychological tests. At the end of this evaluation, their cases were discussed by the service team and the diagnoses established.

\section{Follow-Up}

Behavioral and comorbidity symptoms were reassessed using the CBCL questionnaire. The CBCL has been widely used for screening comorbidity disorders in samples of patients with ADHD (41-43).

Symptom persistence was defined based on the concepts proposed by Biederman et al. (17, 29): (a) subjects meeting full DSMIV criteria for ADHD ("Syndromic Persistence"); (b) subjects meeting sub-threshold DSM-IV criteria [more than half of the symptoms required for a full diagnosis ("Symptomatic Persistence")]; (c) subjects not meeting criteria (a) or (b) but functionally impaired as assessed by the global assessment of functioning (GAF) (37) and displaying a score $\leq 60$ ("Functional Persistence") in the month prior to the subject's 4 -year follow-up assessment. The social reevaluation used the ABEP.

\section{Statistical Analysis}

Statistical Package for the Social Sciences (SPSS) version 20.0 was used for all statistical analyses. The data were analyzed using descriptive statistical procedures for analyzing and testing hypotheses according to the nature of the variables (quantitative or qualitative) and the sample type (independent or paired). The normality analysis in the samples distribution was performed using Kolmorov-Smirnov test. For samples with normal distribution, parametric tests were adopted. The analysis of quantitative variables, involving the comparison of independent samples, used one-way ANOVA and Student's $t$-tests. The analysis of qualitative 
variables in independent samples used the chi-squared test. For data collected longitudinally (including the number of symptoms from the DSM-IV), involving paired samples, the Split-Plot ANOVA for repeated measures, and Student's $t$-test for paired samples were used. For all tests, a significance level of 5\% was established.

\section{Results}

\section{Demographic Results}

Thirty-seven out of the 38 previous ADHD-diagnosed patients were evaluated in the follow-up study. The mean age of the adolescents was $13.1(\mathrm{SD}=2.5)$ for the remittent ones and 12.4 $(\mathrm{SD}=2.1)$ for the persistent patients in the ADHD group, and $12(\mathrm{SD}=1.9)$ in the clinical control group. There were no significant age differences between the two groups $(p=0.86)$. Thirtyone $(83.8 \%)$ boys and $7(16.2 \%)$ girls were in the ADHD group, whereas $15(68.2 \%)$ boys and 7 (31.8\%) girls were in the clinical control group. Male to female ratio in the ADHD group was $4 / 1$. The loss of the healthy subjects was due to an inability to located them $(N=8)$ or to family members' refusal to participate $(N=8)$.

Of the 37 patients, 22 (59\%) had experienced suspension and/or expulsion during the previous school year. In the ADHD group, only seven were treated with methylphenidate. Almost half of our sample, $47 \%(N=14)$ had at least one grade-level repetition during their school progression and 22 patients had received warnings of possible problems/suspensions/expulsions school, in the previous year before the follow-up. One was arrested and was in a prison for teenagers for stealing and the use of psychoactive substances for the third time at the time of data collection.

\section{Persistence of Symptoms}

Twenty-eight out the $37 \mathrm{ADHD}$ patients at follow-up showed symptom persistence (75\%) and 9 (25\%) showed full remission. Symptom persistence was as follows: 13 (46.4\%) fulfilled all diagnostic criteria (syndromic persistence), 10 (35.7\%) fulfilled sub-threshold criteria symptoms (symptomatic persistence), and 5 (17.8\%) had functional impairments (functional persistence).

The descriptive data of the participants and the characteristics of the ADHD group regarding the persistence or absence of symptoms are shown in Table 1.

\section{Frequencies of Comorbidities}

In the sample, $33.1 \%(13 / 37)$ had none of the investigated comorbidities, $13.5 \%$ (5) had at least one comorbid disorder, and $51.3 \%$ (19) had 2 or more disorders. In the persistent ADHD group, only $18 \%(5 / 28)$ did not have comorbidities.

\section{Associations Among Comorbid Disorders and Persistence of Symptoms}

Persistent ADHD was significantly associated with significant rates of ODD $70 \%(n=19)$, CD $70 \%(n=19)$, and affective problems, such as dysthymia (DD) and major depressive episodes (MDD) $74 \%(n=20)$ compared with controls. Remitted patients did not differ from controls (see Table 2).
TABLE 1|Demographic and clinical characteristics of the control and ADHD groups, expressed as means \pm SD or percentage (\%).

\begin{tabular}{|c|c|c|c|c|c|}
\hline & \multirow[t]{2}{*}{ Control } & \multicolumn{2}{|c|}{ ADHD } & \multirow{2}{*}{$\begin{array}{l}\text { ANOVA or } \\
\text { chi-square }\end{array}$} & \multirow[t]{2}{*}{$p$-Values } \\
\hline & & $\begin{array}{c}\text { Remittent } \\
(N=9)\end{array}$ & $\begin{array}{c}\text { Persistent } \\
(N=28)\end{array}$ & & \\
\hline IQ & $122.5(17.7)$ & $83.2(50.8)$ & $90.8(28.7)$ & $F(3,59)=2.26$ & 0.45 \\
\hline Age (years) & $12(1.9)$ & $13.1(2.5)$ & $12.4(2.1)^{a, *}$ & $F(3,59)=1.44$ & $0.01^{\star \star}$ \\
\hline ABEP & $19.7(1.9)$ & $19.3(3.6)$ & $15.9(4.6)^{\mathrm{b}, *}$ & $F(3,59)=0.19$ & $0.001^{*}$ \\
\hline School & $N(\%)$ & $N(\%)$ & $N(\%)$ & $\chi^{2}(2)=0.47$ & $0.01^{\star \star}$ \\
\hline Particular & $12(54)$ & $1(14)$ & $18(64)$ & & \\
\hline Public & $10(46)$ & $6(86)$ & $9(36)$ & & \\
\hline Medication & $N(\%)$ & $N(\%)$ & $N(\%)$ & $\chi^{2}(1)=0.47$ & 0.49 \\
\hline Use & - & $1(88)$ & $6(78)$ & & \\
\hline No & - & $8(12)$ & $22(22)$ & & \\
\hline
\end{tabular}

IQ, intellectual quotient; $A B E P$, socioeconomic classification; GAF, global assessment of functioning.

Data were analyzed by ANOVA and chi-square test.

${ }^{*} p \leq 0.001 ;{ }^{* *} p \leq 0.01 ;{ }^{a}$ Persistent vs. Controls; ${ }^{b}$ Persistent vs. Remittent.

TABLE 2 | Prevalence of comorbidity at follow-up between control and ADHD groups.

\begin{tabular}{|c|c|c|c|c|c|}
\hline & $\begin{array}{l}\text { Persistent } \\
\qquad(N=27)\end{array}$ & $\begin{array}{c}\text { Remittent } \\
\quad(N=9)\end{array}$ & $\begin{array}{c}\text { Controls } \\
(N=19)\end{array}$ & $\begin{array}{c}\text { Test } \\
\text { statistic }\end{array}$ & $p$-Values \\
\hline & $N(\%)$ & $N(\%)$ & $N(\%)$ & & \\
\hline Affective & $20(74)^{a * \star, b * \star}$ & $0(0)$ & $4(21)$ & $\chi^{2}(2)=21.07$ & $<0.001$ \\
\hline Anxiety & $15(55)$ & 3 (33) & 7 (37) & $\chi^{2}(2)=2.21$ & 0.33 \\
\hline Somatic & $8(30)$ & $5(55)$ & $3(16)$ & $\chi^{2}(2)=4.68$ & 0.09 \\
\hline Attentional & $23(85)^{\mathrm{a} \star \star \star,} \mathrm{b \star \star}$ & $3(33)$ & $2(10)$ & Fischer's & $<0.001$ \\
\hline Oppositional & $19(70)^{a *, b * \star}$ & $1(11)$ & $5(26)$ & $\chi^{2}(2)=13.25$ & 0.001 \\
\hline Conduct & $19(70)^{a_{\star \star \star}, b_{\star \star}}$ & $0(0)$ & $1(5)$ & $\chi^{2}(2)=0.47$ & $<0.001$ \\
\hline
\end{tabular}

${ }^{a}=v s$. Controls; ${ }^{b}=v s$. Remittent.

Data were analyzed by chi-square test and Fisher's exact test. ${ }^{*} p \leq 0.05 ;{ }^{* *} p \leq 0.01$.

\section{Discussion}

In this 4-year follow-up, symptomatic persistence was associated with high rates of comorbidities, a low number of patients in treatment for ADHD and school problems.

In the past, it was believed that ADHD symptoms persisted until mild-adolescence, but now there are signs of their often continuing throughout adolescence and into early adulthood (44). Corroborating these findings, our results showed that three quarters of the current sample presented with some type of ADHD symptom persistence 4 years after the first evaluation, and almost half met syndromic persistence criteria. This rate of persistence differs slightly from other follow-up studies. Biederman et al. (30) reported a $35 \%$ persistence rate for full ADHD diagnosis and $22 \%$ when partial remission cases were included, and Mick et al., (8) found $71 \%$ persistence rates. Persistence rates found in this study may reflect the difficulty in recognizing mental health problems in children and adolescents by pediatricians and psychiatrists, and the small number of professionals specializing in child psychiatry in Brazil (45). Across the country, we have few public and private services available to make appropriate diagnoses and afford treatment. In addition, there is great concern in university and 
government sectors over the possible over-treatment of children and adolescents with ADHD in our country. However, in fact, it is estimated that only $16.2-19.9 \%$ of individuals affected by Brazil received first-line treatment for the disorder in 2009-2010 (46).

In reality, the actual number in treatment is probably lower still because these stimulants can also be used for other purposes, though less frequently (46). Thus, a patient with ADHD can remain undiagnosed and untreated for many years, and this may result in increased persistence of symptoms and development of comorbidities. However, these results seem to agree with previous reports documenting that $\mathrm{ADHD}$ is a highly persistent disor$\operatorname{der}(13,17,19,22,25,47,48)$ and that patterns of persistence and remission can be predicted over the long term into young adult life.

The patients included at baseline had a diagnosis of ADHD without comorbidities. Four years later, the comorbidity rate was $75 \%$. This rate was higher than those found in other studies: $46.4 \%$ (49), $46.6 \%$ (35), and 50\% (13). Such differences could perhaps be explained by sample characteristics because in this study the patients were selected from a center specialized in ADHD treatment, a reference in the area, thus potentially composed of patients with more severe forms of the illness and more thus more likely to seek treatment.

In this work, persistent ADHD was associated with significant rates of $\mathrm{ODD}, \mathrm{CD}$, and affective problems compared with controls. This result is consistent with previous studies showing that comorbidities, particularly behavioral problems, are predictors of lifelong ADHD persistence (7, 8, 22, 30, 31, 50). Although the disruptive behavior disorders (ODD and CD) are considered phenomenologically different, comorbidity is very common. Disruptive behavioral disorders (DBD) and ADHD are both characterized by certain patterns of misbehavior among adolescents. Studies have shown that the severity of CD symptoms is associated with comorbid DBD and ADHD. Adolescents diagnosed with comorbid DBD and ADHD had an increased risk for anxiety disorders, depressive disorders, and substance abuse disorders. The comorbidity between DBD and ADHD should be considered in clinical practice because it could indicate more serious problematic behaviors than in the pure disorders alone $(51,52)$.

Regarding ADHD's comorbidity with mood disorder, recently studies have reported depression in 14\% of ADHD children vs. $1 \%$ of those without ADHD (53). A review of comorbid depression in community samples has reported that the rate of MDD in youths with ADHD is 5.5 times higher than in youths without ADHD, with rates ranging from 12 to $50 \%$ (54). Overlapping symptoms between bipolar disorder (BD) and ADHD make differential diagnosis a complex clinical task (55). It is noteworthy that up to $20 \%$ of children diagnosed with ADHD meet the criteria for BD and $50 \%$ of adolescents with $\mathrm{BD}$ meet the criteria for ADHD $(56,57)$. The rate in this 4-year follow-up study differed from others. Possibly the characteristics of our sample could explain the higher rates of comorbidity with affective disorders (poverty, poor access to treatment, low use of medication, and maybe chronic frustration and disappointment of living with untreated or poorly managed ADHD). ADHD's comorbidity with mood disorders (MDD, DD, and BD) emphasizes the need for early detection and intervention to prevent, delay, or reduce its severity and associated impairments associated over time.

In relation to schooling, more than half the experimental group participants had been suspended or expelled in the latest data collection year. Our results confirm previous work showing that ADHD in childhood is associated with dropping out of school, significantly higher rates of repeated grades, tutoring, placement in special classes, reading disability, and fewer years of schooling attained. Thus, ADHD may increase the risk of adverse educational outcomes related to these symptoms in childhood and adolescence $(10,58,59)$.

We observed that the number of children on medication for ADHD was very small (seven patients). Five of the seven patients were of the most favored social class and possibly had easier access to medical services and medication purchase. Despite substantial evidence supporting the efficacy of stimulant medication for children with (ADHD), adherence to stimulant treatment is often suboptimal (60). Many children discontinue the use of medication within the first year due to adverse effects or do not realize the effectiveness of treatment (61). Furthermore, the parent usually makes the healthcare decisions for children, and only some adolescents could make their own decisions. Among the factors that lead to lower adherence to treatment are the following: belief that the symptoms are not a disorder; distrust of the medical system; cost of medication; lack of providers in the community; and lack of insurance coverage (60,62, 63). The data from this work confirm these findings and may be related to difficulties in access to treatment, medication purchase, and the lack of public policies in Brazil. Thus, there is necessity to improve the management of side effects, setting realistic treatment goals and constantly evaluating the success of therapy.

There are limitations to this study. The first is the relatively small sample size, occasioned by the strict inclusion criteria. A second limitation is the gender distribution with few girls, making it difficult to generalize the results. However, the predominance of boys in the sample is consistent with previous studies and in the general population. A third limitation is represented by the sample loss in the control group in the 4-year follow-up.

\section{Conclusion}

Our results are relative to a population with potentially more severe ADHD (because they searched for treatment) and may not correspond with what happens with individuals with ADHD who do not seek treatment. The current analyses suggest that a small number of children with ADHD attain complete remission and the persistence of symptoms might be associated with more psychiatric comorbidities. This can indicate that the comorbid disorder is also persistent, and should encourage clinicians to carefully monitor comorbidities in children with ADHD and to be attentive to the residual manifestations of the symptoms of this disease over time. The results could suggest that a lack of effective pharmacological and psychosocial interventions and early diagnosis could aggravate the core symptoms of ADHD, leading to persistence of symptoms and the development of comorbidities, especially with ODD/CD. However, small number of children and adolescents 
with ADHD were treated effectively throughout the course of the disorder (64), and they tended to be so only for a short time. Thus, clinicians and pediatricians should be encouraged to carefully monitor children with ADHD and observe both manifestations of residual symptoms over time and comorbidassociated disorders. Furthermore, the improvement of the diagnosis of $\mathrm{ADHD}$; frequent monitoring of cases already diagnosed; and the formulation of public health policies for these children and adolescents could have a substantial impact on the development of the disorder. In developing countries, such as Brazil, a better understanding of the long-term

\section{References}

1. Kooij SJ, Bejerot S, Blackwell A, Caci H, Casas-Brugué M, Carpentier PJ, et al. European consensus statement on diagnosis and treatment of adult ADHD The European Network Adult ADHD. BMC Psychiatry (2010) 10:67. doi:10.1186/ 1471-244X-10-67

2. Wilens TE, Dodson W. A clinical perspective of attention-deficit/hyperactivity disorder into adulthood. J Clin Psychiatry (2004) 65(10):1301-13. doi:10.4088/ JCP.v65n1003

3. Biederman J, Monuteaux MC, Kendrick E, Klein KL, Faraone SV. The CBCL as a screen for psychiatric comorbidity in paediatric patients with ADHD. Arch Dis Child (2005) 90:1010-5. doi:10.1136/adc.2004.056937

4. Polanczyk G, Lima MS, Horta BL, Biederman J, Rohde LA. The wordwide prevalence of ADHD: a systematic review a metaregression analysis. Am J Psychiatry (2007) 164:942-8. doi:10.1176/ajp.2007.164.6.942

5. Freitag CM, Hänig S, Palmason H, Meyer J, Wüst S, Seitz C. Cortisol awakening response in healthy children and children with ADHD: impact of comorbid disorders and psychosocial risk factors. Psychoneuroendocrinology (2009) 34:1019-28. doi:10.1016/j.psyneuen.2009.01.018

6. Willcutt EG. The prevalence of DSM-IV attention-deficit/hyperactivity disorder: a meta-analytic review. Neurotherapeutics (2012) 9(3):490-9. doi:10.1007/ s13311-012-0135-8

7. Hart E, Lahey B, Loeber R, Applegate B, Frick P. Developmental change in attention deficit hyperactivity disorder in boys: a four-year longitudinal study. J Abnorm Child Psychol (1995) 23:729-49. doi:10.1007/BF01447474

8. Mick E, Byrne D, Fried R, Monuteaux M, Faraone SV, Biederman J. Predictors of ADHD persistence in girls at 5-year follow-up. J Atten Disord (2011) 15:183-92. doi:10.1177/1087054710362217

9. Faraone SV, Biederman J, Mick E. The age-dependent decline of attention déficit hyperactivity disorder: a meta-analysis of follow-up studies. Psychol Med (2006) 36:159-65. doi:10.1017/S003329170500471X

10. Spencer TJ, Biederman J, Mick E. Attention-deficit/hyperactivity disorder: diagnosis, lifespan, comorbidities and neurobiology. J Pediatr Psychol (2007) 32(6):631-42. doi:10.1093/jpepsy/jsm005

11. Turgay A, Goodman DW, Asherson P, Lasser RA, Babcock TF, Pucci ML, et al. Lifespan persistence of ADHD: the life transition model and its application. Transition Phase Model Working Group. J Clin Psychiatry (2012) 73(2):192-201. doi:10.4088/JCP.10m06628

12. Rasmussen P, Gillberg C. Natural outcome of ADHD with developmental coordination disorder at age 22 years: a controlled, longitudinal, communitybased study. J Am Acad Child Adolesc Psychiatry (2000) 39:1424-31. doi:10. 1097/00004583-200011000-00017

13. Biederman J, Faraone SV, Taylor A, Sienna M, Williamson S, Fine C. Diagnostic continuity between child and adolescent ADHD findings from a longitudinal clinical sample. J Am Acad Child Adolesc Psychiatry (1998) 37(3):305-13. doi: 10.1097/00004583-199803000-00016

14. Willcutt EG, Pennington BF, Chhabildas NA, Friedman MC, Alexander J. Psychiatric comorbidity associated with DSM-IV ADHD in a nonreferred sample of twins. J Am Acad Child Adolesc Psychiatry (1999) 38(11):1355-62. doi:10. 1097/00004583-199911000-00009

15. Schatz DB, Rostain AL. ADHD with comorbid anxiety: a review of the current literature. J Atten Disord (2006) 10:141-9. doi:10.1177/1087054706286698

16. Barkley RA, Guevremont DC, Anastopoulos AD, DuPaul GJ, Shelton TL. Driving-related risks and outcomes of attention deficit hyperactivity disorder in outcomes of children and adolescents with ADHD could help in the implementation of limited financial resources on programs and projects targeted to patients with poor outcome (cases of comorbidity, legal problems, abandonment school, etc.), (65).

\section{Acknowledgments}

The authors would like to thank the AFIP (Association Fund of Incentive to Research) for logistical support. We are grateful to the patients and the volunteers for their participation.

adolescents and young adults: a 3 to 5-year follow-up survey. Pediatrics (1993) 92(2):212-8.

17. Biederman J, Mick E, Faraone SV. Age-dependent decline of symptoms of attention deficit hyperactivity disorder: impact of remission definition and symptom type. Am J Psychiatry (2000) 157:816-8. doi:10.1176/appi.ajp.157.5.816

18. Matza LS, Paramore C, Prasad M. A review of the economic burden of ADHD. Cost Eff Resour Alloc (2005) 9(3):5. doi:10.1186/1478-7547-3-5

19. Barkley RA, Fischer M, Edelbrock CS, Smallish L. The adolescent outcome of hyperactive children diagnosed by research criteria: I. An 8-year prospective follow-up study. J Am Acad Child Adolesc Psychiatry (1990) 29:546-57. doi:10. 1097/00004583-199007000-00007

20. Barkley RA, Fischer M, Smallish L, Fletcher K. The persistence of attentiondeficit/hyperactivity disorder into young adulthood as a function of reporting source and definition of disorder. J Abnorm Psych (2002) 111:279-89. doi:10. 1037/0021-843X.111.2.279

21. Barkley RA, Fischer M, Smallish L, Fletcher K. Young adult follow-up of hyperactive children: antisocial activities and drug use. J Child Psychol Psychiatry (2004) 45:195-211. doi:10.1111/j.1469-7610.2004.00214.x

22. Biederman J, Faraone S, Milberger S, Curtis S, Chen L, Marrs A. Predictors of persistence and remission of ADHD into adolescence: results from a fouryear prospective follow-up study. J Am Acad Child Adolesc Psychiatry (1996) 35:343-51. doi:10.1097/00004583-199603000-00016

23. Claude D, Firestone P. The development of ADHD boys: a 12-year follow-up. Can J Behav Sci (1995) 27:226-49. doi:10.1111/ppe.12097

24. Fischer M, Barkley RA, Smallish L, Fletcher K. Young adult follow-up of hyperactive children: self-reported psychiatric disorders, comorbidity, and the role of childhood conduct problems and teen CD. J Abnorm Child Psychol (2002) 30:463-75. doi:10.1023/A:1019864813776

25. Karam RG, Breda V, Picon FA, Rovaris DL, Victor MM, Salgado CA, et al. Persistence and remission of ADHD during adulthood: a 7-year clinical followup study. Psychol Med (2015) 45:2045-56. doi:10.1017/S0033291714003183

26. Mannuzza S, Klein RG, Bessler A, Malloy P, LaPadula M. Adult outcome of hyperactive boys: educational achievement, occupational rank and psychiatric status. Arch Gen Psychiatry (1993) 50:565-76. doi:10.1001/archpsyc.1993. 01820190067007

27. Mannuzza S, Klein R, Bessler A, Malloy P, LaPadula M. Adult psychiatric status of hyperactive boys grown up. Am J Psychiatry (1998) 155:493-8. doi:10.1176/ ajp.155.4.493

28. Satterfield JH, Schell A. A prospective study of hyperactive boys with conduct problems and normal boys: adolescent and adult criminality. J Am Acad Child Adol Psychiatry (1997) 36:1726-35. doi:10.1097/00004583-19971200000021

29. Yan W. An investigation of adult outcome of hyperactive children in Shanghai. Chin Med J (1996) 109:877-80.

30. Biederman J, Petty CR, Evans M, Small J, Faraone SV. How persistent is ADHD? A controlled 10-year follow-up study of boys with ADHD. J Psychiatry Res (2010) 177:299-304. doi:10.1016/j.psychres.2009.12.010

31. Biederman J, Petty CR, Clarke A, Lomedico A, Faraone SV. Predictors of persistent ADHD: an 11-year follow-up study. J Psychiatr Res (2011) 45:150-5. doi:10.1016/j.jpsychires.2010.06.009

32. Biederman J, Petty CR, Woodworth KY, Lomedico A, Hyder LL, Faraone SV. Adult outcome of attention-deficit/hyperactivity disorder: a controlled 16year follow-up study. J Clin Psychiatry (2012) 73(7):941-50. doi:10.4088/JCP. $11 \mathrm{~m} 07529$ 
33. Lecendreux M, Konofal E, Cortese S, Faraone SV. A 4-year follow-up of attention-deficit/hyperactivity disorder in a population sample. J Clin Psychiatry (2015) 76:712-9. doi:10.4088/JCP.14m09555

34. Klein RG, Mannuzza S, Olazagasti MA, Roizen E, Hutchison JA, Lashua EC, et al. Clinical and functional outcome of childhood attentiondeficit/hyperactivity disorder 33 years later. Arch Gen Psychiatry (2012) 69(12):1295-303. doi:10.1001/archgenpsychiatry.2012.271

35. Cak HT, Dinc GS, Tuzun Z, Evinc SG, Cop E, Cetin FC. Comorbidity and continuity of attention deficit hyperactivity disorder (ADHD) from childhood to adolescence in Turkey. Atten Defic Hyperact Disord (2013) 5:353-60. doi:10. 1007/s12402-013-0114-x

36. Anselmi L, Menezes AMB, Barros FC, Hallal PC, Araújo CL, Domingues MR, et al. Early determinants of attention and hyperactivity problems in adolescents: the 11-year follow-up of the 1993 Pelotas (Brazil) birth cohort study. Cad Saúde Pública (2010) 26(10):1954-62. doi:10.1590/S0102-311X2010001000012

37. American Psychiatric Association. Diagnostic and Statistical Manual of Mental Disorders. 4th ed. Washington, WA: American Psychiatric Association (2000). p. 85-93.

38. Mattos P, Serra-Pinheiro MA, Rohde LA, Pinto D. Apresentação de uma versão em português para uso no Brasil do instrumento MTA-SNAP-IV de avaliação de sintomas de transtorno do déficit de atenção/hiperatividade e sintomas de transtorno desafiador e de oposição. Revista de Psiquiatria do Rio Grande do Sul (2006) 28(3):290-7. doi:10.1590/S0101-81082006000300008

39. Duarte CS, Bordin IAS. Instrumentos de avaliação. Rev Bras Psiquiatr (2000) 22(Supl II):55-8. doi:10.1590/S1516-44462000000600015

40. Associação Brasileira de Empresas de Pesquisa. (2007). Available from: www. abep.org

41. Biederman J. Attention-deficit/hyperactivity disorder: a selective overview. Biol Psychiatry (2005) 57:1215-20. doi:10.1016/j.biopsych.2004.10.020

42. Geeraerts SB, Deutz MH, Deković M, Bunte T, Schoemaker K, Espy KA, et al. The child behavior checklist dysregulation profile in preschool children: a broad dysregulation syndrome. J Am Acad Child Adolesc Psychiatry (2015) 54:595.e-602.e. doi:10.1016/j.jaac.2015.04.012

43. Hetlinger CA, Simpkins CG, Combs-Orme T. Using the CBCL to determine the clinical status of children in state custody. Child Youth Serv Rev (2000) 22:55-73. doi:10.1016/S0190-7409(99)00073-0

44. Schmitz M, Polanczyk G, Rohde LA. TDAH: remissão na adolescência e preditores de persistência em adultos. J Bras Psiquiatr (2007) 56(Supl 1):25-9. doi:10.1590/S0047-20852007000500006

45. Tanaka OY, Lauridsen-Ribeiro E. Ações de saúde mental na atenção básica: caminho para ampliação da integralidade da atenção. Ciênc Saúde Coletiva (2009) 14(2):477-86. doi:10.1590/S1413-81232009000200016

46. Mattos P, Rohde LA, Polanczyk GV. O TDAH é subtratado no Brasil. Rev Bras Psiquiatria (2012) 34:513-51. doi:10.1016/j.rbp.2012.04.002

47. Lambert NM, Hartsough CS, Sassone D, Sandoval J. Persistence of hyperactivity symptoms from childhood to adolescence and associated outcomes. Am J Orthopsychiatry (1987) 57(1):22-32. doi:10.1111/j.1939-0025.1987. tb03505

48. Weiss G, Hechtman L, Milroy T, Perlman T. Psychiatric status of hyperactives as adults: a controlled prospective 15 -year follow-up of 63 hyperactive children. J Am Acad Child Psychiatry (1985) 24(2):211-20. doi:10.1016/S0002-7138(09) 60450-7

49. Kessler RC, Berglund P, Demler O, Jin R, Merikangas KR, Walters EE. Lifetime prevalence and age-of-onset distributions of DSM-IV disorders in the national comorbidity survey replication. Arch Gen Psychiatry (2005) 62:593-602. doi:10. 1001/archpsyc.62.6.617

50. Molina BS, Hinshaw SP, Swanson JM, Arnold LE, Vitiello B, Jensen PS, et al. MTA at 8 years: prospective follow-up of children treated for combined-type ADHD in a multisite study. J Am Acad Child Adolesc Psychiatry (2009) 5:484-500. doi:10.1016/j.jaac.2012.12.014
51. Jensen CM, Steinhausen HC. Comorbid mental disorders in children and adolescents with attention-deficit/hyperactivity disorder in a large nationwide study. Atten Defic Hyperact Disord (2014) 7(1):27-38. doi:10.1007/s12402-0140142-1

52. Nordström T, Ebeling H, Hurtig T, Rodriguez A, Savolainen J, Moilanen I, et al. Comorbidity of disruptive behavioral disorders and attention-deficit hyperactivity disorder - indicator of severity in problematic behavior? Nord J Psychiatry (2013) 67(4):240-8. doi:10.3109/08039488.2012.731431

53. Larson K, Russ SA, Kahn RS, Halfon N. Patterns of comorbidity, functioning, and service use for US children with ADHD, 2007. Pediatrics (2011) 127:462-70. doi:10.1542/peds.2010-0165

54. Daviss WB. A review of co-morbid depression in pediatric ADHD: etiologies, phenomenology, and treatment. J Child Adolesc Psychopharmacol (2008) 18(6):565-71. doi:10.1089/cap.2008.032

55. Silva KL, Rovaris DL, Guimarães-da-Silva PO, Victor MM, Salgado CA, Vitola ES, et al. Could comorbid bipolar disorder account for a significant share of executive function deficits in adults with attention-deficit hyperactivity disorder? Bipolar Disord (2014) 16(3):270-6. doi:10.1111/bdi.12158

56. Kowatch RA, DelBello MP. Pharmacotherapy of children and adolescents with bipolar disorder. Psychiatr Clin North Am (2005) 28(2):385-97. doi:10.1016/j. psc.2005.02.001

57. Pliszka SR. The MTA at 8. J Am Acad Child Adolesc Psychiatry (2009) 48(11):1122. doi:10.1097/CHI.0b013e3181ba3dd9

58. Barkley RA. Attention-Deficit Hyperactivity Disorder, A Handbook for Diagnosis and Treatment. 3rd ed. New York: Guilford Press (2006). p. 25-6.

59. Fredriksen M, Dahl AA, Martinsen EW, Klungsoyr O, Faraone SV, Peleikis DE. Childhood and persistent ADHD symptoms associated with educational failure and long-term occupational disability in adult ADHD. Atten Def Hyp Disord (2014) 6(2):87-99. doi:10.1007/s12402-014-0126-1

60. Coletti DJ, Pappadopulos E, Katsiotas NJ, Berest A, Jensen PS, Kafantaris V. Parent perspectives on the decision to initiate medication treatment of attention-deficit/hyperactivity disorder. J Child Adolesc Psychopharmacol (2012) 22(3):226-37. doi:10.1089/cap.2011.0090

61. Toomey SL, Sox CM, Rusinak D, Finkelstein JA. Why do children with ADHD discontinue their medication? Clin Pediatr (Phila) (2012) 51(8):763-9. doi:10. $1177 / 0009922812446744$

62. Charach A, Fernandez R. Enhancing ADHD medication adherence: challenges and opportunities. Curr Psychiatry Rep (2013) 15(7):371. doi:10.1007/s11920013-0371-6

63. Fiks AG, Mayne S, Hughes CC, Debartolo E, Behrens C, Guevara JP, et al. Development of an instrument to measure parents' preferences and goals for the treatment of attention deficit-hyperactivity disorder. Acad Pediatr (2012) 12(5):445-55. doi:10.1016/j.acap.2012.04.009

64. Perwien A, Hall J, Swensen A, Swindle R. Stimulant treatment patterns and compliance in children and adults with newly treated attentiondeficit/hyperactivity disorder. J Manag Care Pharm (2004) 10:122-9.

65. Biederman J, Faraone SV, Spencer T, Mick E, Monuteaux M, Aleardi M. Functional impairments in adults with self-reports of diagnosed ADHD: a controlled study of 1001 adults in the community. J Clin Psychiatry (2006) 67(4):524-40. doi:10.4088/JCP.v67n0403

Conflict of Interest Statement: The authors declare that the research was conducted in the absence of any commercial or financial relationships that could be construed as a potential conflict of interest.

Copyright $(2015$ Palma, Natale and Calil. This is an open-access article distributed under the terms of the Creative Commons Attribution License (CC BY). The use, distribution or reproduction in other forums is permitted, provided the original author(s) or licensor are credited and that the original publication in this journal is cited, in accordance with accepted academic practice. No use, distribution or reproduction is permitted which does not comply with these terms. 